\title{
O QUE É MINISTÉRIO PÚBLICO?
}

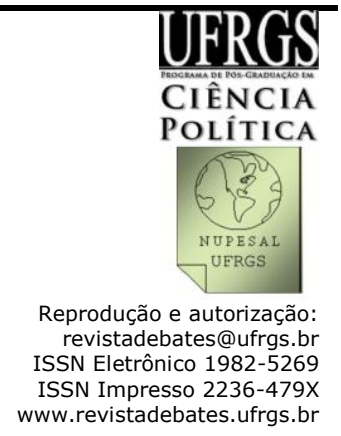

ABREU, Alzira Alves de. O que é o Ministério Público? Rio de Janeiro: FGV Editora, 2010. 124 p.

Boa parte dos estudantes e técnicos de Direito, dos juristas, dos pesquisadores das ciências sociais aplicadas e das ciências humanas, além de curiosos em geral, já fizeram essa pergunta que serve de título e de ponto de partida a Alzira Alves de Abreu, doutora em Sociologia pela Universidade Paris $\checkmark$ Sorbonne e pesquisadora do CPDOC da Fundação Getúlio Vargas. Em linguagem clara e concisa, a acadêmica examina a instituição que, após a promulgação da Constituição Federal em 1988, ocupa os noticiários, os debates públicos e o imaginário social.

Fruto de pesquisas, artigos e livros - sendo um destes o capítulo $O$ Ministério Público do Estado do Rio de Janeiro: atuação e relação com a imprensa, publicado pela autora na obra coletiva Direitos e Cidadania, coordenada pela historiadora Ângela de Castro Gomes (2007), fonte do capítulo 5 da obra resenhada - "O que é o Ministério Público?" apresenta inicialmente síntese do histórico da instituição cuja autonomia - conquistada na Carta Magna - ampliou seus limites: antes, restrita ao papel de auxiliar do Executivo e ao de carrasco nas querelas criminais; em seguida, defensora do meio-ambiente, do consumidor, da ordem jurídica, dos direitos difusos e coletivos, da cidadania.

As diferenças entre o Ministério Público de outros países e o nacional concentram-se na estrutura do Estado, na relação com a polícia, nos mecanismos de seleção de seus quadros ou nos limites e obstáculos de atuação, sofrendo ou contrapondo-se ao controle político. As comparações estendidas aos Estados Unidos, França, Alemanha, Itália, Portugal, Espanha, Rússia e Cuba - constatam, no Brasil, recuos e avanços por meio das leis, das Constituições - democráticas ou ditatoriais, de movimentos e associações de membros do Ministério Público.

O segundo capítulo destaca os critérios de ascensão hierárquica. Para subir ao posto máximo - no âmbito estadual, Procurador-Geral de Justiça - os 
interessados precisam atingir idade mínima (35 anos), dez anos na carreira, ocupar o cargo de Procurador de Justiça. Procuradores e Promotores são eleitores, contudo o governador indica o eleito entre os três mais votados ratificando, na maioria dos casos (73\%), conforme diagnóstico do Ministério da Justiça em 2006, o nome consagrado no sufrágio.

O Ministério Público mantém a função constitucional com a eleição do novo Procurador-Geral de Justiça que selecionará as áreas consideradas importantes ou deficitárias, promovendo, por exemplo, iniciativas que facilitem o acesso da população aos órgãos jurisdicionais. O Ministério Público de alguns Estados (Paraná, Goiás, Bahia e São Paulo) investiu na descentralização, transportando servidores públicos e equipamentos à periferia. Os promotores de Paraná e Goiás predominantemente orientam e ratificam acordos sobre investigação de paternidade e ação de alimentos. São Paulo opta pela parceria entre secretarias - entre elas, a do Trabalho, Desenvolvimento Social e Habitação. Já o Ministério Público do Rio Grande do Sul empenha-se "[...] contra a má utilização de recursos públicos locais [...]. No ano 2000, chegava a 300 o número de prefeitos investigados e a 108 os que sofreram punições" (ABREU, 2010, p. 38).

O Ministério Público, nos Estados, atua no âmbito cível, criminal, eleitoral, execuções penais, fundações, infância e juventude, desdobrando-se em ramos especializados como Ministério Público Militar, do Trabalho, do Distrito Federal e Territórios e, com um ponto de interrogação, Eleitoral. Com exceção do Eleitoral - composto por integrantes tanto da esfera federal quanto das estaduais, os demais possuem estruturas próprias.

De acordo com a obra, constrói-se gradualmente a legitimidade institucional: primeiro, na Lei da Ação Civil Pública; depois, na Constituição Federal; por fim, no estatuto legal próprio que assegura - como alternativa de inibir ou minimizar a impunidade - a abertura de inquérito civil e a defesa de direitos individuais indisponíveis, difusos e coletivos.

Para Abreu, as limitações são perceptíveis: sobressaem os critérios de escolha dos chefes da instituição, indicados pelo Presidente com apoio do Senado ou pelos governadores. A interferência cria problemas que, numa primeira leitura, denunciam articulações políticas: 1) mandato fixo não garante independência ou desligamento total do Chefe do Executivo; 2) eventuais perseguições ou distribuição de privilégios a grupos que se oponham ou se alinhem às novas diretrizes; 3 ) restrição de candidatos somente os procuradores atingem o topo da hierarquia, motivo pelo qual significativa parte dos promotores $(83,7 \%)$ defende eleição direta, democrática e transparente, atrelada aos princípios republicanos, em detrimento de menor parcela de procuradores que ratificam condições paritárias $(65,8 \%)$; 4) gestão administrativa e condições de funcionamento que aproximam/submetem o Procurador-Geral de Justiça ao Executivo e ao Legislativo, considerando que temas como reestruturação da carreira, ampliação do número de promotores, aumento de salário e melhoria das condições físicas de trabalho são negociados com o Governador, responsável 
pela introdução de tais reivindicações no Orçamento, aprovado pela Assembléia Legislativa.

A partir de 2000, a tutela coletiva, antes concentrada nas mãos do Procurador-Geral de Justiça, desloca-se às dos promotores que, amparados na independência funcional e na inamovibilidade, desempenham suas atividades sem interferências externas. Se, por um lado, a independência alcança bons resultados, por outro, dentro da própria instituição, críticas contundentes surgem contra os procedimentos de fiscalização de atos de abuso de poder, prestação de contas à sociedade, níveis de burocratização, índices de eficiência, controle da administração pública e defesa da probidade/moralidade administrativa.

Em 2006, a Secretaria de Reforma do Judiciário, vinculada ao Ministério da Justiça, em parceria com o Conselho Nacional de ProcuradoresGerais do Ministério Público (CMPG) e a Associação Nacional dos Membros do Ministério Público (CONAMP), promoveu pesquisa com os membros do Ministério Público dos Estados. Apenas 27,5\% responderam aos questionários, apontando, entre os principais empecilhos, problemas no orçamento, instituição desaparelhada e sem funcionários, insuficiência de promotores em proporção de cem mil habitantes, defasagem ainda mais alarmante nas zonas rurais e nos estados pobres. O levantamento indicou a média de idade: promotores, 40 anos; procuradores, 58. Mais homens do que mulheres, maioria de cor branca. Católicos predominam, seguidos de espíritas. Menos de $20 \%$ dos promotores e de $10 \%$ dos procuradores matriculam-se em cursos de pós-graduação. Dos pós-graduados, a maioria e os mais titulados concentram-se nas regiões Sudeste e Sul.

A pesquisadora ainda salienta as mudanças sucessivas sofridas, tendo colaborado, para alcançar o estágio corrente, o projeto de "reengenharia institucional" encetado pelo órgão fluminense: depois de constatar a ausência de instrumentos que analisassem resultados e catapultassem seus integrantes a titulares das disputas judiciais, efetivou ajustes às novas competências constitucionais. Entre elas, o poder investigatório.

A querela sobre a faculdade de inquirição do Ministério Público - titular da ação penal e legítimo acusador - envolve interesses antagônicos. A Constituição Federal confere à polícia tal finalidade sem, no entanto, proibí-la ao parquet que, assim como o INSS (Instituto Nacional de Seguridade Social) ou a Receita Federal, procederia as investigações sem contrariar leis ou afrontar a Carta Magna. Detentora de método próprio de averiguação e mantendo-se intocada, a polícia acredita na perda de poder caso se submeta ao Ministério Público, fiscal de suas atividades. Os procedimentos adotados no inquérito podem decidir o rumo da ação penal. Entre os opositores à capacidade investigativa, os policiais e a Ordem dos Advogados do Brasil $(\mathrm{OAB})$.

$\mathrm{Na}$ perspectiva da socióloga, os integrantes do Ministério Público arrogam-se as funções de defesa dos interesses sociais alçando-se, dessa maneira, garantidores da cidadania. O Ministério Público do Trabalho atua na 
erradicação do trabalho escravo e do infantil, contra a discriminação, a precariedade da saúde e as fraudes, a favor da segurança no ambiente de trabalho e da inserção de deficientes físicos na rotina laboral. Já o Ministério Público Estadual consolida sua imagem de defensor do povo e reposiciona socialmente os promotores e, por tabela, os juízes, por meio de ações de grande repercussão como o cerco ao jogo do bicho, desencadeado no Rio de Janeiro, e o combate à máfia dos fiscais, em São Paulo.

Ainda distingue-se na defesa do meio-ambiente (apurando denúncias de ocupação irregular do solo urbano e solucionando conflitos sem recorrer ao poder judiciário), do consumidor (tanto nos direitos individuais indisponíveis, difusos e coletivos quanto nos interesses individuais homogêneos), das populações indígenas (saúde, educação e demarcação de terras), da criança, do adolescente e do idoso (examinando as denúncias de violação dos direitos infanto-juvenis, principalmente as de violência física e sexual e as de trabalho ilegal; já em relação aos idosos, inspeciona limitações físicas e mentais, abandono, internação em asilos, restrições ou discriminações).

Abreu destaca que o Ministério Público recebe críticas ao poder de investigação. Dois casos de repercussão nacional merecem destaque. O primeiro deles, a Chacina da Candelária, ocorrida no Rio de Janeiro em 1993. Ação conjunta do Ministério Público, da Polícia Militar e da Polícia Civil resultou conclusões apressadas. Sob pressão da imprensa, os órgãos envolvidos e o poder judiciário cometeram erros: equívocos da Polícia Civil omitidos ou ignorados, condenação de inocentes, fragilidade ou inexistência de provas. O segundo caso remete à prisão do Diretor de Florestas do Ibama, em Mato Grosso, em 2005, durante perseguição aos contrabandistas de madeira. Solicitado pelo Ministério Público Federal, o encarceramento mostrou-se desnecessário: sem provas contra o funcionário, (re)conhecido pelo trabalho na defesa do meio-ambiente, o Procurador jogou a responsabilidade pelo desastre da operação na Polícia Federal.

O último capítulo aborda a politização. Enfatiza as ponderações de juristas segundo as quais a falta de critérios objetivos permite ações baseadas em convicções pessoais. A politização da justiça - ou judicialização da política - consistiria no excesso de uso do judiciário na defesa de direitos sociais.

As interpretações de que os promotores e procuradores estariam politizando suas ações, nos levam a estabelecer a distinção entre a politização e a atuação ideológica partidária. Muitos membros do Ministério Público, ao assumir a defesa dos interesses da sociedade, da democracia, são identificados de forma negativa, pois estariam atuando politicamente. $\mathrm{Na}$ verdade, eles estão atuando politicamente dentro dos preceitos constitucionais. Poucos são os que atuam, de fato, engajados partidariamente, e esses recebem fortes críticas dentro da própria instituição (ABREU, 2010, p. 101). 
Questionamentos estendem-se igualmente às relações com a mídia cujos profissionais - menos burocráticos e mais ágeis - divulgam notícias sem buscarem a verdade. Embora o acesso da população aos fatos aconteça pela imprensa, o denuncismo - denúncias inconsistentes - causa grandes estragos, tanto na esfera pública quanto na particular, fomentando movimentações de adeptos de projetos de lei que limitam e impõem censuras - como o da Lei da Mordaça - aos integrantes do Ministério Público.

"O que é o Ministério Público?" apresenta panorama da instituição que, nos últimos vinte anos, construiu e consolidou a imagem de defensora da sociedade. Entre acertos e equívocos, fincou-se no cotidiano brasileiro. Imprescindível o trabalho de Alzira Alves de Abreu aos que desejam estudá-la sociológica, filosófica ou juridicamente, constatando-se, desde já, uma ausência e um caminho.

Conquanto saliente, nas notas finais, a função de "apresentar um resumo do processo de formação e atuação" do Ministério Público, o livro silencia sobre as corregedorias e o Conselho Nacional do Ministério Público (CNMP), inserido na Constituição Federal em 2004.

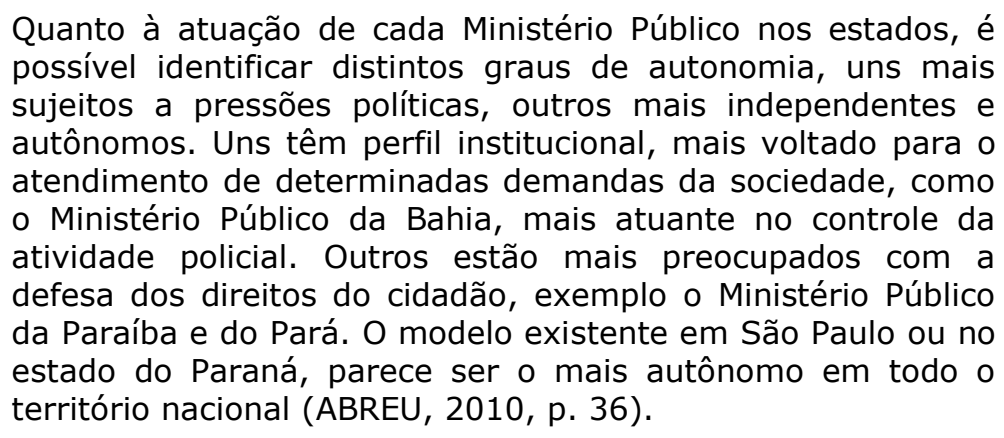

Embora o foco do trabalho ora resenhado não seja este, o fragmento acima abre um caminho para discutir tema nevrálgico a qualquer órgão, instituição ou grupo. Concordamos integralmente - com a autora e a Constituição Federal - de que o Ministério Público é uno e indivisível. Uno e indivisível, entretanto sem identidade. Como órgãos, instituições ou grupos deslocam-se no campo social, político ou jurídico sem identidade? Uma hipótese às próximas pesquisas.

Mestre em História pela Universidade Estadual Paulista Júlio de Mesquita Filho (UNESP - Assis/SP) e membro do Grupo de Pesquisa Cotidiano, Direito e Construção da Sociabilidade, coordenado pelo Prof. Dr. Jayme Wanderley Gasparoto, vinculado à UNESP - campus de Marília/SP.

E-mail: vicrenos@yahoo.com.br 


\section{RESENHAS}

\section{Referências}

ABREU, Alzira Alves de. O Ministério Público do Estado do Rio de Janeiro: atuação e relação com a imprensa. In: GOMES, Ângela de Castro (Org.). Direitos e Cidadania: justiça, poder e mídia. Rio de Janeiro: FGV, 2007. p. 93116.

Texto recebido em 30/09/2012. Aprovado em 13/11/2012. 